\title{
The power of competition: reducing or reinforcing discrimination?
}

Citation for published version (APA):

Schwieren, C. A. A., Vendrik, M. C. M., \& de Gijsel, P. P. (2004). The power of competition: reducing or reinforcing discrimination? METEOR, Maastricht University School of Business and Economics. METEOR Research Memorandum No. 041 https://doi.org/10.26481/umamet.2004041

Document status and date:

Published: 01/01/2004

DOI:

10.26481/umamet.2004041

Document Version:

Publisher's PDF, also known as Version of record

\section{Please check the document version of this publication:}

- A submitted manuscript is the version of the article upon submission and before peer-review. There can be important differences between the submitted version and the official published version of record.

People interested in the research are advised to contact the author for the final version of the publication, or visit the DOI to the publisher's website.

- The final author version and the galley proof are versions of the publication after peer review.

- The final published version features the final layout of the paper including the volume, issue and page numbers.

Link to publication

\footnotetext{
General rights rights.

- You may freely distribute the URL identifying the publication in the public portal. please follow below link for the End User Agreement:

www.umlib.nl/taverne-license

Take down policy

If you believe that this document breaches copyright please contact us at:

repository@maastrichtuniversity.nl

providing details and we will investigate your claim.
}

Copyright and moral rights for the publications made accessible in the public portal are retained by the authors and/or other copyright owners and it is a condition of accessing publications that users recognise and abide by the legal requirements associated with these

- Users may download and print one copy of any publication from the public portal for the purpose of private study or research.

- You may not further distribute the material or use it for any profit-making activity or commercial gain

If the publication is distributed under the terms of Article $25 \mathrm{fa}$ of the Dutch Copyright Act, indicated by the "Taverne" license above, 


\title{
The power of competition: reducing or reinforcing discrimination?
}

\author{
Christiane Schwieren* \\ (Universitat Pompeu Fabra) \\ Maarten Vendrik \\ (Universiteit Maastricht) \\ Peter de Gijsel \\ (Universiteit Utrecht)
}

\begin{abstract}
Economic theory argues that competition can diminish discrimination in the labor market, while arguments from social psychology's social-identity theory point into the opposite direction. We ran two experiments to test the psychological predictions in an 'economic' setting. Participants were categorized artificially and played a team game, facing either strong or weak competition. They further had to choose a new team member from either of the categories, and pay for enactment of their preference. Only under strong competition, subjects were willing to pay for their preference. The result gives qualified support to the prediction from social-identity theory.
\end{abstract}

Keywords: discrimination, competition, social identity, experiment.

JEL Code: J71, C92

\footnotetext{
${ }^{*}$ Corresponding author. Universitat Pompeu Fabra, Department of Economics and Business, Ramon Trias Fargas 25 - 17; 08005 Barcelona, Spain. Tel.: +34 93542 2688; Fax: +34 93542 1746; e-mail: christiane.schwieren@upf.edu
}

Acknowledgements: We want to thank Joep Sonnemans, Jos Theelen, Jens Grosser, and other members of the CREED-team in Amsterdam for providing most valuable help conducting the experiments. 


\section{Introduction}

Discrimination in the labor market is still surprisingly persistent. Because of this persistence even in societies striving to eliminate it, a lot of research in economics, (social) psychology, and related disciplines deals with this topic. One stream of research in economics is interested in the question how product market competition influences discrimination. An important argument is that under certain conditions competition has the power to diminish or even stop discriminatory behavior [e.g., Becker (1957)]. However, a prominent socialpsychological theory, social-identity theory [SIT, e.g., Turner et al. (1986)], would rather predict the contrary, but has not yet been applied in an economic context.

This paper incorporates SIT into a microeconomic model and presents two experiments to test the predictions derived. Our model integrates Becker's approach to discrimination, statistical discrimination theory [e.g., Phelps (1972); Arrow (1973)], SIT, and stereotyping research [e.g., Fiedler (2000)]. While economic approaches assume that competition makes discriminatory behavior costly when no actual productivity differences between groups exist, and thus will make it disappear in the long run, SIT makes the opposite prediction. People are said to identify strongly with their ingroup when they are in a state of self-relevant uncertainty ${ }^{1}$, and this can lead to strengthened discrimination against an outgroup - especially if this outgroup is negatively stereotyped. Strong competition in the product market can be such a situation of self-relevant uncertainty [see Vendrik \& Schwieren (2004)]

We describe two experiments conducted to test whether the 'psychological' predictions of the integrated model find any support in an economic setting. To our knowledge this is a first attempt to directly analyze discrimination in the labor market experimentally. In our experiments several teams were engaged in a task which represented 'production' of a product sold on a market. This market was either strongly competitive, represented by low output prices, or weakly competitive, represented by higher output prices.

\footnotetext{
${ }^{1}$ Self-relevant uncertainty is uncertainty about important things for the life and the self of a person, for example having a job, being able to make a living, or succeeding in some important task.
} 
In both experiments subjects were categorized artificially, but some information was given about performance of the two categories, to make participants develop a stereotype of each category (see below). Discrimination was measured by asking participants two things: First, whether they had a preference for a person of their own or the other category as a new member for their team. Second, we asked whether and how much they were willing to pay for getting the preferred new member with a higher probability than 50:50 (which was the default probability). Consistent with the predictions from social-identity theory, the experiments found a payment in the strongly competitive situation only, but it tended to be in favour of the outgroup.

The organization of the paper is as follows. First, section two shortly describes the theoretical background and model underlying the experiments, and develops the hypotheses. Section three describes the two experiments and discusses their results. Section four concludes with a general discussion.

\section{Theoretical background and hypotheses}

\subsection{Theories}

The most influential economic theories on discrimination in the labor market are Becker's theory of employer discrimination and statistical discrimination theory (Phelps; Arrow). Our research refers to both approaches, however assuming that there are no (longer) actual differences in the distribution of productivities between the discriminated and nondiscriminated group. In Becker's model, discrimination in hiring or wages is caused by a 'taste for discrimination' of the employer, which makes him willing to pay higher wages to members of his preferred group to be able to work only with them. However, in a competitive environment employers with such discriminatory tastes will have a cost disadvantage vis-àvis non-discriminating employers since the latter will hire (more) - equally qualified members of the discriminated group for lower wages. When increasing competition suppresses profits to zero in the long run, this allows the non-discriminating employers to drive the discriminating employers out of the market. Moreover, in a shorter run, an income effect of falling profits (Comanor, 1973) induces discriminating employers to diminish their discriminatory behavior. 
However, employees may also have a taste for discrimination, and this discrimination not necessarily disappears under competition in the product market. But many of today's firms are structured in teams, with flat hierarchies. This means that (high-skilled) employees are also employers, taking part in hiring decisions and sharing in profits, i.e. being directly affected by the situation of the firm. This may especially hold for jobs on the level of middle or higher management. In such a situation employee discrimination is vulnerable to competitive conditions in the product market as well. If there is imperfect information about productivities of applicants, discriminatory tastes of employers and employees tend to be rationalized into incorrect perceptions of a difference in average or variance of productivities between the discriminated and non-discriminated groups (Arrow, p. 26). This renders the discrimination statistical (i.e., it is discrimination against individuals because of (perceived) differences between groups with respect to productivity), but since the perceptions are not backed by actual differences in productivity between the two groups, this 'weak' variant of statistical discrimination will be vulnerable to competition in the product market in the same way as Becker's discrimination.

Dealing with teams making hiring decisions, one is drawn to social-psychological literature on discrimination. Social-Identity Theory [SIT, Turner et al.], and its extension Self-Categorization Theory [SCT, e.g., Haslam et al. (1996)] are prominent socialpsychological theories dealing with discrimination. As they do not explicitly discuss labor market situations, one has to extrapolate from their more general findings. Applying SIT to labor market situations, the conclusion is very different from Becker's. SIT states that selfcategorization in terms of a salient ingroup can, under certain circumstances, lead to discriminatory attitudes and behavior. Circumstances leading to strong self-categorization are, for example, situations of high self-relevant uncertainty, i.e. uncertainty about things, which are important for a person, like profits for an employer. Situations of strong competition can, in the eyes of an employee or employer, be perceived as giving rise to strong self-relevant uncertainty, for several reasons. For the employer it is never sure whether he can stay in the market - which is also (self-)relevant for his employees. Furthermore, we assume imperfect information about productivities of employees, which constitutes self-relevant uncertainty in situations of strong competition for the same reason - hiring badly performing employees can 
reduce the chances of survival of the firm. Therefore, SIT would for discrimination in the labor market rather predict more than less discrimination in the labor market when competition gets stronger.

An important channel by which ingroup identification leads to more discrimination is a stronger reliance on stereotypes [e.g., Turner et al.]. Discrimination on the basis of stereotypes is basically the same as statistical discrimination - with the difference that psychological research predicts that even when there are no longer any actual differences between the two groups, the stereotype can persist. Reasons for this persistence can be, among others, rationalization of prejudice (the emotional component of discrimination that underlies Becker's taste; see above) or a bias in the perception of bigger ingroup samples versus smaller out-group samples [(Fiedler et al. (1999)]. In another paper, Vendrik and Schwieren develop a theoretical model which integrates all these concepts and explains in more detail how increasing competition in the product market may induce profit-sharing teams (e.g. partnerships) to rely more on wrong stereotypes and prejudices about groups in their hiring and pay decisions, and hence to discriminate more. It does so by showing that 'psychological' effects may dominate counteracting 'economic' effects. The current paper presents a first experimental test of this theoretical model, which is therefore shortly explained in the following section.

\subsection{Model}

The kind of economic situation our experiments try to mimic is the following. A number of firms produce the same homogeneous good and sell it in the same competitive market. The number of competitors in this market is so large as to make them effectively price takers. The internal structure of the firms is that of teams of partners who collectively produce the good and collectively take decisions on, among other things, hiring of new members. All team members receive a fixed base wage as well as an equal share in the profits of the team. New team members can be hired from a certain ingroup as well as the corresponding outgroup. Within these groups marginal team productivities $q_{i}$, i.e. marginal contributions of new team members to the prevailing team production, may differ, but 
between the groups no actual differences in the distribution of $q_{i}$ exist $^{2}$. Nevertheless, team members have stereotypic perceptions $\bar{q}^{S}$ of the average marginal team productivity $\bar{q}$ of the two groups in favor of the ingroup. (Emotional) prejudices may play a role in that and are supposed to be fully rationalized into the incorrect stereotypic perceptions $\bar{q}^{s}$. The discrimination coefficient of a team $D$, i.e. the additional amount of money the team is willing to pay on average for hiring a member of one group instead of the other, is then given by product price $p$ times the average expected difference $\Delta \hat{q}$ in $q_{i}$ between candidate members from the ingroup and the outgroup. This $\Delta \hat{q}$ is based on the difference $\Delta \bar{q}^{S}$ in stereotypic perceptions $\bar{q}^{S}$ of ingroup and out-group, but also on indications that there is no actual difference in $\bar{q}$ between the ingroup and outgroup. Then $\Delta \hat{q}$ can be shown to equal $S \Delta \bar{q}^{S}$, where the extent of using stereotypes $S \in[0,1]$ is equal to the perceived reliability of $\Delta \bar{q}^{S}$ relative to the sum of perceived reliabilities of $\Delta \bar{q}^{S}$ and the indications of $\Delta \bar{q}=0$ (see Vendrik and Schwieren for a derivation for an analogous case).

Increasing competition is conceived as a rise in supply relative to demand in the product market near the equilibrium price $p$. This leads to a fall in $p$. Increasing competition elicits more self-relevant uncertainty, and hence more identification with the ingroup, and this is assumed to raise $S$ or $\Delta \bar{q}^{S}$, or both. ${ }^{3}$ The team discrimination coefficient $D=p S \Delta \bar{q}^{S}$ will then rise as well if the relative rise in $S \Delta \bar{q}^{S}$ is stronger than the relative fall in $p$. Results of Vendrik and Schwieren suggest that this may especially hold for lower $p$, i.e. when competition is strong. However, since it may not hold for all ranges of $p$, the experiments only tested the direction of change in $S \Delta \bar{q}^{S}=D / p .{ }^{4}$

In addition, the experiments measured the strengths of discriminatory preferences of individual team members in a cardinal way since there may be a discrepancy between the effects of competition on discriminatory preferences as stated by way of this measure and the

\footnotetext{
${ }^{2}$ They might have existed in the past, when they were learned, but they have not persisted until today.

${ }^{3}$ In the model of Vendrik and Schwieren there is also a counteracting 'economic' effect due to increases in screening expenditures on individual candidates. This 'economic' effect is not incorporated in the experiments reported here since information on individual candidates was not provided (see Sec. 3 for an explanation).

4 When competition increases in the other product markets of the economy as well, $p$ can be interpreted as an indicator of the general price level. In that case $D / p$ corresponds to the real discrimination coefficient.
} 
effects of competition on discriminatory preferences as revealed in the willingness to pay $D / p .^{5}$ Notwithstanding this discrepancy, the stereotypic perceptions $\bar{q}^{s}$ in favor of the ingroup are expected to lead to a stated preference for an ingroup member. Furthermore the strength of this stated preference is supposed to rise with the expected productivity difference between candidate members from the ingroup and the outgroup, $\Delta \hat{q}=S \Delta \bar{q}^{S}$, when competition increases. $^{6}$

\subsection{Hypotheses}

In the experiments the stated discriminatory preferences and the willingness to pay $D / p$ were measured under conditions of weak and strong competition. On the basis of the theoretical analysis given above we formulate four hypotheses:

H1) In general, a new team member from the ingroup is preferred over a new team member from the outgroup.

H2) Under strong as compared to weak competition, a new team member from the ingroup is preferred more strongly over a new team member from the outgroup.

H3) In general, an additional payment is made for a new team member from the ingroup rather than for a new team member from the outgroup.

H4) Under strong as compared to weak competition, a higher additional payment is made for a new team member from the ingroup than for a new team member from the outgroup.

\footnotetext{
${ }^{5}$ Experimental psychologists often doubt whether there is a direct link between stated 'attitudes' and behavior (see, e.g., Eagly \& Chaiken, 1998). Having to pay for the enactment of a preference is a 'stronger' test than just having to state a preference.

${ }^{6}$ If the stated preferences were consistent with the revealed preferences, a theoretical measure for the stated preferences is the disutility $D U$ of each team member's discrimination coefficient $D / N$, where $\mathrm{N}$ is the number of team members. This $D U$ is given by $D U=U^{\prime}(\Pi / N) p S \Delta \bar{q}^{S} / N$, where $U^{\prime}(\Pi / N)$ is each team member's marginal utility of income as determined by the profit share $\Pi / N$. The product $U^{\prime}(\Pi / N) p / N$ indicates the subjective importance of the expected productivity difference ingroup $S \Delta \bar{q}^{S}$ in each team member's discriminatory preferences. Approximating $U^{\prime}(\Pi / N)$ by a power function, Vendrik and Schwieren show that for the range of powers found in empirical research this subjective importance rises when competition increases. This then reinforces the positive effect of the assumed rise in $S \Delta \bar{q}^{S}=D / p$ on the discriminatory preferences.
} 
Hypotheses 1 and 3 are supposed to hold because of the assumption of a more or less reliable $(S<1)$ stereotypic perception $\Delta \bar{q}^{S}$ in favor of the ingroup. Hypotheses 2 and 4 are expected to hold because an increase in competition is assumed to lead to higher self-relevant uncertainty, and hence to stronger identification with the ingroup and consequently a higher $S \Delta \bar{q}^{S}$. The intermediating psychological processes were not tested during the experiments since this could have influenced subjects' behavior either in the direction of socially desirable (i.e., not-discriminating) behavior, or as a demand-effect ${ }^{7}$. Still, to get indications about the relevance of these processes, some of the pertinent variables were measured at the end of the experiment. This cannot be counted as a real test, as they in turn could have been influenced by the decisions taken.

\section{The experiments}

To our knowledge this is the first attempt to directly analyze discrimination in the labor market in a laboratory experiment. However, experiments on discrimination in general have been done in social psychology as well as in experimental economics. Prominent examples of social-psychological research on discrimination are the minimal-group experiments developed by Tajfel et al. (1971), on which we partly rely for our design. Other social-psychological experiments focused on prejudice, e.g. studies using the Implicit Attitude Test [see, e.g., Greenwald \& Banaji (1995)]. In experimental economics, discrimination has been studied for example by Fershtman \& Gneezy (2001) in the context of trust games. Experiments on the influence of status in markets also can be seen as dealing with discrimination of lower-status traders (and women), who have been found to get paid less for the things they are selling in an auction ran by Bell et al. (2001).

\subsection{Design}

Our experiments were designed such that it would be possible to control the effect of the stereotype of the categories. Participants were provided with a stereotype of the two categories blue and red, the (evaluative) content of which was known to the researchers. This

\footnotetext{
${ }^{7}$ Psychologists assume that participants in experiments try to find out how they are expected to behave and consequentially behave the way they are expected. An effect is called a demand effect if it was very obvious
} 
was done following the mechanism proposed by Fiedler et al. (see below). Artificial categories were used to avoid uncontrolled effects of existing stereotypes, such as a stereotype becoming salient which is not relevant here, but influences behavior. Examples for this would be the stereotype that women are worse than men in a mathematical task like the one used in the experiment, but also a contrary stereotype that female students are more cooperative and put more effort in everything they do at the university than male students. As far as such stereotypes have some ground in reality, we want to avoid them in our experiments since these focus on pure group discrimination in the absence of actual productivity differences between the groups. Furthermore, the use of artificial categories helped to reduce social-desirability concerns - the fact that subjects know that one should not discriminate against women.

Discrimination was operationalized as any preference for a new member based on belonging to a category in a situation where no actual difference in productivity distribution between categories exists. Participants did not have any individual information about the possible new members and also could not acquire it. This was the easiest way to guarantee that subjects had the same average information about members of both groups. Giving information about individual members of the two groups could lead to evaluative differences between the categories, which of course would distort the mechanisms assumed. ${ }^{8}$ At no point an explicit and clear link between performance and category membership was drawn.

Subjects first had to indicate a preference. In a second step they were asked to pay for enactment of this preference. Payments raised the probability of getting a new team member from the preferred category above the initial $50 \%$ chance. Since we wanted to measure the direction of change in $S \Delta \bar{q}^{S}=D / p$ rather than that in $D$ itself, the amounts of money $\widetilde{D}$ that subjects were willing to pay (as a team) for getting a preferred new member with a higher chance had to be expressed as fractions or percentages of the output price $p$. The relation

how subjects were supposed to behave and their behaviour was mainly influenced by the 'demand' characteristics of the design.

${ }^{8}$ This could happen in an experiment with artificial categories and no a priori evaluative differences between the categories, because subjects would start to develop a picture of the categories in the experiment based on the individual information they get. This is not relevant for real-life situations, at least in the short run, as 'real' stereotypes have been developed over a long time and are quite resistant to change by exposure to inconsistent information. 
between the experimental $\widetilde{D} / p$ and the theoretical $D / p$ is derived in Appendix A. The experimental $\widetilde{D} / p$ is likely to be a monotonously increasing function of the theoretical $D / p$ for not too low and not too high values of $D / p$. Conversely, this means that a higher value of $\widetilde{D} / p$ found in the experiments implies a higher value of the underlying $D / p=S \Delta \bar{q}^{S}$. Thus, under the assumptions made in Appendix A, a significant direction of change in $\widetilde{D} / p$ found in the experiments gives an unambiguous indication of the direction of change in the perceptions $\Delta \hat{q}=S \Delta \bar{q}^{S}$. However, since we could not determine the size of change in $\Delta \hat{q}=S \Delta \bar{q}^{S}$, we could not combine this with the information on the imposed variation in the output price $p$ (see below) to find the direction of change in the discrimination coefficient $D=p S \Delta \bar{q}^{S}$. To approximately maximize the chance of finding significant differences in $\widetilde{D} / p$, and hence in $D / p$, under different strengths of competition, subjects had to pay $15 \%$, $30 \%, 45 \%, 60 \%$ or $75 \%$ of the output price $p$ of the last round to raise the probability of hiring the preferred member by successive steps of 10\% (see Appendix A for a derivation). Thus, by paying $75 \%$ they got the preferred member for sure (see Table 1 ).

Table1: Percentages of p paid and corresponding probability changes

\begin{tabular}{|l|l|l|l|l|l|l|}
\hline Percentage of $p$ paid & 0 & 15 & 30 & 45 & 60 & 75 \\
\hline $\begin{array}{l}\text { Probability to get the preferred new member (in } \\
\text { \%) }\end{array}$ & 50 & 60 & 70 & 80 & 90 & 100 \\
\hline
\end{tabular}

Competition was operationalized as either high or low output prices $p$. High $p$ result from weak competition on the supply side of the output market, while low $p$ are a result of strong competition on the supply side. Teams have to perform as well as possible to get as many points (money) as possible. In a situation with high $p$, already for low output a relatively high amount of money is earned. On the other hand, when $p$ is low, a high level of output is necessary to make some earnings. Self-relevant uncertainty then exists in the sense of 'risk of getting no (or low) rewards' in both experiments. 
The design of the experiments borrows from economic and psychological experimental methodology, which differ in certain respects [see, e.g., Hertwig \& Ortmann (2001)]. In economic experiments subjects are usually paid depending on their performance, and there is generally no (need for) deception of the subjects. In psychological experimentation, often situations are studied were performance-based payment is not feasible, because there is no clear performance criterion. In some cases deception of the subjects about certain aspects or the real purpose of the experiment is necessary, because otherwise measurement of the variables of interest is hardly or not at all possible. In our experiments it was possible to pay subjects performance-based, though not directly for the most important, the 'hiring' decision, but for general performance. To avoid getting only socially desirable answers, and to link the experiments with the existing research on social-identity theory, artificial categories were used, but no deception of the subjects.

\subsection{Experiment 1}

\section{Subjects}

80 students (54 males, 26 females) from various faculties of the University of Amsterdam participated in teams of four members in four sessions of five teams each.

\section{Material}

The experiment was computerized using the software $\mathrm{z}$-Tree developed by Fischbacher (1999), and was conducted in the experimental laboratory of CREED at the University of Amsterdam. All instructions were given on paper, but all tasks were done via the computer. ${ }^{9}$ Division into categories (blue and red) was done by random assignment of subjects to computers. The real-effort task consisted of multiplying pairs of numbers randomly generated by the computer.

\section{Procedure}

Upon arrival, subjects were randomly assigned to a computer, which defined their category (blue or red), and they got the first instructions. The first part of the experiment consisted of a stereotype-generation task designed following Fiedler et al., in which subjects had to practice the real-effort task they had to do later (the multiplications). They then got

\footnotetext{
${ }^{9}$ Instructions will be made available on the first author's web page.
} 
selective feedback about the performance of members of the two categories in the following way. Of all results of the practice period some were selected and presented sequentially on the screen, such that for the blue category 16 instances of good and 8 instances of poor performance were shown, compared to 8 instances of good and 4 instances of poor performance for the red category. The information was presented on the screen in the following way: 'Calculation number $\mathrm{x}$ : someone of the category blue/red did this correctly/wrongly'. With respect to the mean and higher-order moments of the distribution of performance this information was the same for both categories. Fiedler et al. show how such a pair of distributions can lead to the impression that the category with more information available performs better. This results in a 'wrong' stereotype, which 'rationally' should not play a role in decision-making.

After this stereotype-generation task, subjects were distributed into three homogeneous 'blue' teams and two 'spare' teams (one 'red'-only team and one mixed team). The 'discrimination' measure consisted of one question asking subjects whether they would prefer a new member to be rather from their own or the other category. The 'spare' teams were necessary because 'new members' for later rounds were needed. They needed to have some experience with the game, because otherwise they could be expected to perform worse than 'old' members.

Teams first played two rounds of the real-effort game. In the strong-competition treatment 'output prices', i.e., the money subjects got for each correct multiplication, varied between 0.75 and 1.25 guilders $(€ 0.34-€ 0.57)$. In the weak competition treatment, these output prices varied between 1.25 and 1.75 guilders ( $€ 0.57-€ 0.79$ ). Output prices were given as a range to enhance uncertainty, while still giving subjects some information so that they could develop expectations. This models a situation of competition with imperfect information quite closely. Teams had one minute for 'production' in each round. Each team started with a minus of four guilders ( $€ 1.80)$, representing wages for team members $(€ 0.45$ per team member and round). Any gains teams made were distributed equally among all members. Subjects got feedback on group performance of the own group (not on exact output prices) after each round. 
After two rounds, members of the blue teams were asked to choose a new member for their team, which they would get from the spare teams. They could indicate (the strength of) their preference for either a red or a blue new member using a scrollbar from zero to 100, zero meaning a very strong preference for a blue new member and 100 a very strong preference for a red new member. Those who had indicated a preference for either a blue or a red new member were then asked how much they were willing to pay to enhance the probability of getting the preferred member. The four-person team had to make this payment together, which means that each subject privately only had to pay one fourth of the price. After all subjects had submitted their decisions, the computer randomly chose one team member of each team whose decision was finally implemented. New teams were formed and payments were made if applicable. Three more rounds were played in the new teams. After the fifth round the experiment was concluded with a questionnaire, asking about, among other things, sex of the participant, identification with the own category and subjective evaluations of each category. Subjects were asked which category they thought performed on average better on the task, using the same kind of scrollbar as for measuring the preference. This measure was implemented to find out whether subjects did relate performance to category membership at all. Identification was measured with one question, using a vertical scroll-bar ranging from zero to four. We do not use answers to these questions for the main analysis, because they are influenced by what happened during the experiment. They are only used to get a general picture of how participants perceived the situation.

Finally, subjects were paid individually, based on their performance. There was no show-up fee paid, but subjects could expect from the announcements to earn something between 15 and 30 Dutch Guilders (about $€ 8$ and $€ 15$ ).

\section{Results}

Experiment 1 is analyzed using aggregate data on a team basis as members of one team got the same feedback and data of individuals thus are not independent. All teams were included in the analysis. As the sample still is rather small, non-parametric Man-Whitney-U tests were used for comparisons between treatments. If not indicated otherwise, significance tests for correlations were performed 1-tailed, following the specification of the hypotheses. 
In the following, we refer to SCT when talking about the strong-competition (or low-outputprice) treatment and to WCT when talking about the weak-competition (or high-output-price) treatment. Descriptive statistics of the results are shown in Table 2.

Table 2: Descriptive statistics for the most important variables

\begin{tabular}{|c|c|c|c|c|c|c|}
\hline Treatment & & $\mathrm{N}$ & Minimum & Maximum & Mean & Std. Deviation \\
\hline \multirow[t]{4}{*}{ All data } & Preference for new member & 12 & 29.00 & 73.25 & 49.06 & 13.29 \\
\hline & Payment (in $\%$ of $p$ ) & 12 & .00 & 15.00 & 5.31 & 4.65 \\
\hline & Evaluation of category & 12 & 17.75 & 68.25 & 43.04 & 14.37 \\
\hline & Identification & 12 & .25 & 2.50 & 1.23 & .59 \\
\hline \multirow[t]{4}{*}{ WCT } & Preference for new member & 6 & 29.00 & 62.75 & 43.33 & 11.81 \\
\hline & Payment (in $\%$ of $p$ ) & 6 & .00 & 11.25 & 3.75 & 4.11 \\
\hline & Evaluation of category & 6 & 17.75 & 68.25 & 41.04 & 16.20 \\
\hline & Identification & 6 & .25 & 1.50 & 1.00 & .45 \\
\hline \multirow[t]{4}{*}{$\mathrm{SCT}$} & Preference for new member & 6 & 38.00 & 73.25 & 54.79 & 13.05 \\
\hline & Payment (in $\%$ of $p$ ) & 6 & 3.75 & 15.00 & 6.88 & 4.98 \\
\hline & Evaluation of category & 6 & 26.25 & 61.25 & 45.04 & 13.51 \\
\hline & Identification & 6 & .75 & 2.50 & 1.46 & .66 \\
\hline
\end{tabular}

Hypothesis 1 assumed that in general a new team member from the ingroup is preferred over a new member from the outgroup. A t-test shows that overall the preference measure does not differ significantly from 50, i.e., there is no significant preference for one of the categories $(\mathrm{t}=-.24, \mathrm{p}=.81$ (2-tailed)). Looking at preferences for each category separately, both preference for blue and preference for red differ significantly from zero (blue: $\mathrm{t}=2.9, \mathrm{p}=.008$; red: $\mathrm{t}=2.28, \mathrm{p}=.022$ ). Together this indicates that there are approximately as many participants preferring their own category as there are participants preferring the other category. Thus, there is no evidence for Hypothesis 1.

Hypothesis 2 tested whether the effect proposed in Hypothesis 1 becomes stronger (or appears) for stronger competition. To test this, preferences were compared between treatments. No significant difference was found $(\mathrm{Z}=-1.44$, as. sig. $=.150$ (2-tailed)). However, there is a difference between treatments with respect to which preferences become 
significantly different from zero ${ }^{10}$ : Preference for a blue new member differs significantly from zero in WCT, but only marginally significantly in SCT (WCT: $t=2.62, p=.023$; SCT: $t$ $=1.51, \mathrm{p}=.095)$. Preference for a red new member, on the other hand, differs significantly from zero in SCT; but not in WCT (WCT: $\mathrm{t}=1.00, \mathrm{p}=.182$; SCT: $\mathrm{t}=2.17, \mathrm{p}=.042$ ). Hypothesis 2 therefore did not find support either, and the additional test even shows that it is rather new members from the outgroup which are preferred stronger when competition strengthens, while preferences for ingroup members weakens.

Hypothesis 3 predicted that additional payment is made for a new team member from the ingroup rather than for a new member from the outgroup: A U-test shows that there is no significant difference in amount of payment for blue and red new members $(Z=-.78$, as. sig. $=.44$ (2-tailed)). Payments for both categories separately differ significantly from zero (payment for red: $\mathrm{t}=2.16, \mathrm{p}=.025$, for blue $\mathrm{t}=2.24, \mathrm{p}=.02$ ). Thus, there was no evidence for Hypothesis 3 as payments are made for new ingroup and new outgroup members equally.

To test the prediction of Hypothesis 4 that strong competition leads to higher levels of payment for ingroup members, it was tested between treatments whether there is a difference in payment for each category. We find a marginally significant difference in payment for a red new member between the two treatments, payment being higher in SCT (for red: $\mathrm{Z}=$ 1.80 , as. sig. $=.072$; for blue: $\mathrm{Z}=-.73$, as. sig. $=.465$ (2-tailed)). A U-test for each of the treatments testing whether there is more payment for the ingroup than for the outgroup could not be calculated due to the small sample size. Payment for a blue new member differs marginally significantly from zero in both treatments, whereas payment for red does not differ from zero in WCT, but it significantly does so in SCT (WCT: Payment for red: $\mathrm{t}=1.0, \mathrm{p}=$ .187 ; for blue $\mathrm{t}=1.75, \mathrm{p}=.070$; SCT: For red $\mathrm{t}=2.24, \mathrm{p}=.035$; for blue $\mathrm{t}=1.58, \mathrm{p}=.085$ ). Thus, Hypothesis 4 also does not find support as more payment is made for outgroup members when competition is stronger. Table 3 shows descriptive statistics and U-tests for these results.

\footnotetext{
${ }^{10}$ This test was performed 1-tailed, as values below zero were not possible. This holds for all similar tests of difference from zero.
} 
Table 3: Descriptive statistics and Man-Whitney U tests between treatments

\begin{tabular}{cccccc}
\hline \multirow{2}{*}{ Treatment } & & N & Mean & Std. Deviation Std. Error Mean \\
\hline WCT & Preference for blue new member & 6 & 8.79 & 8.23 & 3.36 \\
& Preference for red new member & 6 & 2.13 & 5.21 & 2.13 \\
& Payment for red new member & 6 & .63 & 1.53 & .63 \\
& Payment for blue new member & 6 & 3.13 & 4.38 & 1.79 \\
SCT & Preference for blue new member & 6 & 3.21 & 5.19 & 2.12 \\
& Preference for red new member & 6 & 8.00 & 9.05 & 3.69 \\
& Payment for red new member & 6 & 5.63 & 6.16 & 2.52 \\
& Payment for blue new member & 6 & 1.25 & 1.94 & .79 \\
\hline
\end{tabular}

\begin{tabular}{ccccc}
\hline & \multicolumn{3}{c}{ Preference for Preference for Payment for } & \multicolumn{2}{c}{ Payment for } \\
& blue & red & red & blue \\
\hline Mann-Whitney U & 10.00 & 10.00 & 8.00 & 14.00 \\
$Z$ & -1.37 & -1.43 & -1.80 & -.73 \\
Asymp. Sig. (2-tailed) & .171 & .153 & .072 & .465 \\
\hline
\end{tabular}

\section{Further exploratory analyses}

We tested additionally whether there is in general more payment when competition is stronger. After excluding one outlier ${ }^{11}$, the difference is marginally significant, i.e., significant on the $10 \%$ level $(Z=-1.91$, as. sig. $=.056$ (2-tailed)). Subjects are willing to pay slightly more in SCT than in WCT.

Secondly, we tested for differences in performance evaluation of the two categories: Overall, positive evaluation of the blue category is significantly different from zero, while positive evaluation of the red category is only marginally significantly different from zero (for blue $\mathrm{t}=3.30, \mathrm{p}=.004$, for red $\mathrm{t}=1.71, \mathrm{p}=.058$ ).

Evaluation of the performance of both categories correlates significantly with the feedback the group got in the round before the decision was made $(r=.65, p=.021)$, i.e., the

\footnotetext{
${ }^{11}$ Outliers were identified following the standard definition given for box plot diagrams in SPSS as values between 1.5 - 3 box lengths from the median. The box length corresponds to the interquartile range, i.e., the difference between the $75^{\text {th }}$ and $25^{\text {th }}$ percentiles.
} 
more positive the feedback, the more subjects thought that blue new members performed better than red new members and vice versa. This feedback also correlates marginally significantly with preference $(\mathrm{r}=.57, \mathrm{p}=.053)$, i.e., the worse the own (blue) team did, the stronger is the preference for a red (i.e., outgroup) new member.

Finally, identification with the own category was in general low (mean $=1.23$, std. dev. $=.59 ;$ split by treatment: WCT: mean $=1.00$, std. dev. $=.45 ;$ SCT: mean $=1.46$, std. dev. $=.66)$.

\section{Discussion}

For an interpretation of the results several problems of the data have to be considered.

First, feedback about performance of the own team was given after each round, and this influenced the evaluation of the categories and probably also preferences, even if the feedback was not relative, i.e., subjects did not know whether their team scored good or bad in comparison to other teams. The influence of this feedback could well have been stronger than the effect of the stereotype induction from the beginning of the experiment.

Secondly, as data had to be analyzed aggregated by group, the number of independent observations per treatment was quite low. Therefore, non-parametric methods had to be used, making it more difficult to detect existing effects.

Overall, the results show a quite complex pattern. Basically, none of the hypotheses found support. In the strong-competition treatment, outgroup bias in the preferences was found while in the weak competition treatment there was some ingroup bias in addition to outgroup bias (with respect to preferences). However, this did hardly result in payment for new members of this category, which illustrates that stated (ingroup) preferences do not always translate into behavior. Hypothesis 4 did not find support in the current formulation, but the underlying idea was confirmed: There was more payment in SCT than in WCT.

Spears et al. (2001) report that groups feeling lower in status or performance often favor the outgroup, especially if they do not identify very strongly with their category which both probably was the case in the experiment reported here. Identification was in general low. Subjects got overall quite negative feedback about their own performance - and this feedback influenced their preferences. Outgroup bias was stronger when subjects got more negative feedback about performance of their own group, i.e., when they felt lower in 
performance (status). Outgroup bias therefore can be explained as economically rational behavior. But, only under strong competition did subjects rely on the information about performance of the categories they inferred from feedback.

Experiment 1 thus provided evidence for an interplay of 'economic' and 'psychological' factors, but not precisely in the way our theoretical model predicted: The role of 'economic' factors became visible in that under strong competition all information which could be seen as 'diagnostic' for performance of the new member was used 'rationally'. As subjects obviously believed that categories contained productivity-related information, this could be interpreted as a weak form of statistical discrimination since there were no actual productivity differences between the categories. However, subjects believed in the categoryrelated information only when competition was strong, which is in line with SIT's prediction that in situations of self-relevant uncertainty stronger identification leads to more use of stereotypes. This is evidence that weak statistical discrimination based on wrong beliefs about category differences strengthens when competition strengthens. Interestingly payment was nearly only found in relation to outgroup bias. This suggests that subjects showing ingroup bias in their preferences are more aware of the 'non-economic' motivations they might have for preferring one category over the other.

A second computerized experiment was conducted without giving group feedback. That way the influence of feedback on the perception of the categories could be avoided and a larger amount of independent data was available, as we now could analyze the data by individual subject. Furthermore, by pointing participants explicitly to the number of red and blue members in the game (enabling them to relate the pieces of information to group size, if they wanted), it was made easier for them to detect that the information was in general the same for both groups. Doing this, we had a stronger test for the assumption that subjects 'knowingly' use 'irrelevant' information to base their decisions on.

\subsection{Experiment 2}

\section{Subjects}


72 students from various faculties of the University of Amsterdam (47 males, 25 females) participated in four sessions of 20 res. 12 persons each.

Material

Basically the same material as in Experiment 1 was used.

\section{Procedure}

The two experiments differed with respect to the feedback subjects got after each round: Now there was no feedback at all. A further difference was that participants were explicitly pointed to the number of blue/red-category members in the game, as described before.

\section{Results}

Unfortunately, for one session only twelve participants showed up. But, there were no significant differences in any of the relevant variables between participants in this session and those in the comparable 20-participants session. The session is therefore included in the analysis. Some participants indicated in the final questionnaire that they already participated in similar experiments, but as their data did not differ significantly from the other data in any of the relevant variables, it was included in the analysis too.

This time data was analyzed on an individual basis, because there was no feedback given to the teams during the experiment. Table 4 shows the descriptive statistics of the most important variables for both treatments.

For a test of Hypothesis 1, we analyzed whether there is a difference in preferences between the two treatments. A t-test shows that again general preference does not differ significantly from 50 (indifference between red and blue; $\mathrm{t}=1.18, \mathrm{p} .=.25$ (2-tailed)). When analyzing preference for blue and preference for red separately, we find again that they both differ highly significantly from zero (blue: $\mathrm{t}=3.31, \mathrm{p}=.002$; red: $\mathrm{t}=4.17, \mathrm{p}=.000$ ), implying that subjects do have preferences for either of the categories. Again, we find no evidence for Hypothesis 1. 
Table 4: Descriptive statistics of the most important variables

\begin{tabular}{|c|c|c|c|c|c|}
\hline treatment & $\mathrm{N}$ & Minimum & Maximum & Mean & Std. Deviation \\
\hline \multirow[t]{4}{*}{ All data } & Preference for new member 44 & 0 & 100 & 54.93 & 27.84 \\
\hline & Payment (in $\%$ of $p$ ) 44 & 0 & 45 & 4.09 & 9.36 \\
\hline & Evaluation of category 44 & 9 & 100 & 50.77 & 22.53 \\
\hline & Identification 44 & 0 & 4 & 1.20 & 1.27 \\
\hline \multirow[t]{4}{*}{ SCT } & Preference for new member 24 & 0 & 100 & 51.75 & 29.92 \\
\hline & Payment (in $\%$ of $p$ ) 24 & 0 & 45 & 6.25 & 11.63 \\
\hline & Evaluation of category 24 & 9 & 100 & 49.79 & 22.37 \\
\hline & Identification 24 & 0 & 4 & 1.13 & 1.23 \\
\hline \multirow[t]{4}{*}{ WCT } & Preference for new member 20 & 4 & 100 & 58.75 & 25.36 \\
\hline & Payment (in $\%$ of $p$ ) 20 & 0 & 15 & 1.50 & 4.62 \\
\hline & Evaluation of category 20 & 11 & 100 & 51.95 & 23.24 \\
\hline & Identification 20 & 0 & 4 & 1.30 & 1.3 \\
\hline
\end{tabular}

Hypothesis 2 supposes that when competition is stronger, preference for an ingroup member is stronger as well. However, the data show that preferences do not differ between SCT and WCT $(\mathrm{Z}=-1.359$, as. sig. $=.174(2$-tailed $))$. Differences in preference for blue and in preference for red between the two treatments do not become significant (for preference for red: $Z=-.756$, as. sig. $=.45$; for preference for blue $Z=.44$, as. sig. $=.66$ (2-tailed); see Table 5 for descriptive statistics). Contrary to the results of Experiment 1, in WCT only preference for red differs significantly from zero $(\mathrm{t}=2.89, \mathrm{p}=.006)$, whereas in SCT preferences for both categories differ significantly from zero $($ red: $t=2.92, p=.006$; blue $t=$ $2.88, \mathrm{p}=.006)$.

Hypothesis 3 tested whether more payment is made for team members from the own group in general. There is no difference in payment between red and blue new members $(\mathrm{Z}=$ .00 , as. sig. $=1.00)$. Payment for blue and for red new members differs significantly from zero (blue: $\mathrm{t}=1.95, \mathrm{p}=.029$; red: $\mathrm{t}=2.01, \mathrm{p}=.026$ ). Hypothesis 3 thus again did not find support.

Finally, to test Hypothesis 4 that stronger competition leads to more payment for new members from the ingroup, we looked at payment in both treatments separately. As expected 
after Experiment 1, the willingness to pay for any preference is marginally significantly stronger in SCT than in WCT $(Z=-1.61$, as. sign. = .054). Only in SCT, general payment for any of the categories differs significantly from zero $(t=2.63, p=.015)$. Split by category, both payment for red and payment for blue new members are significantly different from zero in SCT, but not in WCT (WCT: blue: $\mathrm{t}=1.00, \mathrm{p}=.17$; red: $\mathrm{t}=1.00, \mathrm{p}=.17$; SCT: blue: $\mathrm{t}=$ $1.70, \mathrm{p}=.052$; red: $\mathrm{t}=1.81, \mathrm{p}=.042$; see Table 5 for descriptive statistics and U-tests). Again, no U-test comparing statistically payment for red and payment for blue in each of the treatments could be made because of the sample size. Thus, the same result for Hypothesis 4 as in the first experiment was achieved.

Table 5: Descriptive statistics and Man-Whitney U-tests between treatments

\begin{tabular}{ccccc}
\hline Treatment & & N & Mean & Std. Deviation \\
\hline Low output prices & Preference for red & 24 & 11.04 & 19.97 \\
& Preference for blue & 24 & 9.29 & 16.79 \\
& Payment for blue & 24 & 2.50 & 7.22 \\
& Payment for red & 24 & 3.75 & 10.13 \\
High output prices & Preference for red & 20 & 12.55 & 20.37 \\
& Preference for blue & 20 & 3.80 & 11.31 \\
& Payment for blue & 20 & .75 & 3.35 \\
& Payment for red & 20 & .75 & 3.35 \\
& & & & \\
\hline
\end{tabular}

\begin{tabular}{ccccc}
\hline & \multicolumn{3}{c}{ Preference for red Preference for blue Payment for blue Payment for red } \\
\hline Mann-Whitney U & 191.00 & 202.50 & 171.00 & 171.50 \\
Z & -1.30 & -1.13 & -1.01 & -1.32 \\
Asymp. Sig. (2-tailed) & .193 & .260 & .310 & .186 \\
\hline
\end{tabular}

\section{Further exploratory analyses}

As in the second experiment no feedback about performance was given to participants during the game, we could check not only whether subjects did relate category membership and performance at all, but we could also test whether evaluations were related to preferences. 
Relationships of preferences and payment with the evaluation of the categories: Both the (positive) evaluation of the red and the blue category separately differ significantly from zero (blue: $\mathrm{t}=4.00, \mathrm{p}=.000$; red: $\mathrm{t}=3.39, \mathrm{p}=.001$ ).

Overall, preferences are strongly correlated with the evaluation (made afterwards!) that a certain category performed better on the task $(r=.77, \mathrm{p}=.000)$.

Payment for each category is (marginally) significantly correlated with (positive) evaluation of both categories (blue: $r=-.24, p=.056$, red: $r=.26, p=.042$ (1-tailed)). Split by treatment, these correlations remain significant in SCT, but not in WCT: Only one subject in WCT wants to pay for a blue new member, and only few for red new members (SCT: blue: $\mathrm{r}=-.34, \mathrm{p}=.050$; red: $\mathrm{r}=.49, \mathrm{p}=.007$; WCT: blue: $\mathrm{r}=-.05, \mathrm{p}=.413$; red: $\mathrm{r}=-.32, \mathrm{p}=.082$ ).

Identification again was low in general (all data mean $=1.2$, std. dev. $=1.27$; SCT mean $=1.13$, std. dev. $=1.23$, WCT mean $=1.3$, std. dev. $=1.3$ )

Sex differences: We also tested for sex differences, which in fact existed: In general, women pay more for their preferences $(Z=-3.04$, as. sig. $=.002)$, and they are also stronger identifying than men $(\mathrm{Z}=-2.21, \mathrm{p}=.027$ (both 2-tailed)).

\section{Discussion}

In the second experiment most results from the first experiment could be replicated. Again, when competition was stronger, more payments for the preferred member were made, and preferences tended towards outgroup bias. Contrary to the first experiment, now in WCT only outgroup bias with respect to preferences was found. This time, it was possible to see whether preferences and payment are linked to performance expectations. Especially when competition was strong, new members of the category perceived as performing better were preferred. In SCT evaluation of the category correlated with payment, i.e., more payments were made for the group perceived as performing better, which was not always the ingroup. However, as evaluation has been assessed at the end of the experiment, this can also be an indication of rationalization of behavior.

As there was no feedback given and the belief that the ingroup was performing badly could not develop that easily, there was more ingroup bias with respect to stated preferences and payment in SCT than in Experiment 1. Low opinion about the performance of one's own category could now not be derived from feedback on own-group performance, but may have 
been based on the opinion subjects had about their personal performance. Again, in WCT hardly any payments were made, and payment for blue new members was not or only marginally significantly different from zero in any of the conditions.

In this second experiment, however, stronger competition did also lead to ingroup bias with respect to preference and payment, which is more in line with the predictions of socialidentity theory. Overall, the results of Experiment 2 do again not confirm our hypotheses, but they provide more evidence for a combination of 'psychological' and 'economic' factors playing a role in the determination of discriminatory preferences and behavior.

\section{General Discussion}

The two experiments provide evidence for a combination of psychological and economic mechanisms, but not in the way our hypotheses predicted. In both experiments, a significant number of subjects uses the - irrelevant - category information as basis for decision-making, and more so, when competition is stronger. Subjects in the second experiment also believe that the category they choose performs better than the other one. This is in line with the predictions about the psychological mechanism of identification (which has not been submitted to a direct test here). It can also be a sign of rationalization of behavior. In both experiments, subjects under weak competition as well as under strong competition have preferences for one of the categories, but under weak competition they are less willing to pay for their preferences, probably because they know that these preferences are based on either just ingroup identification or very unreliable information.

A general result therefore is that competition makes subjects believe in the informational content of the categories and makes them use the categories as a proxy for performance of the possible new member. This is some first evidence for the proposed combination of psychological and economic mechanisms in determining discriminatory behavior: The psychological mechanisms make subjects use the category information and have preferences for any of the groups at all. Economically rational behavior makes them refrain from paying for 'irrational' preferences - when competition is weak. When competition is strong, psychological mechanisms seem to lead to a stronger belief in the usefulness of the category information. 'Economic' mechanisms again make subjects use this information in a 'rational' way. This can be described as a weak form of statistical 
discrimination. Usually, it is assumed that statistical discrimination based on wrong perceptions of productivity differences should disappear when competition gets stronger. The different finding here is a new aspect with respect to weak statistical discrimination: it can become stronger or just appear when competition becomes stronger.

Why did we find so much outgroup bias? One reason could be the fact that artificial categories were used. Aspects like status of the categories and specific contents of stereotypes of a category, which have a strong influence in real life, did not exist in this experimental setting. Furthermore, only performance stereotypes, and not prejudice about the two categories, played a role. The real-world categories labor market discrimination usually applies to are stereotypically linked with good rather than bad ingroup performance of the discriminating group. However, also in the real world minority groups sometimes do show outgroup bias: An example is discrimination against female or black employees by female or black employers. The finding that subjects in the experiments were more willing to pay for outgroup preferences might result from a kind of self-deception: Subjects may realize when perceiving ingroup bias that this might be a bias, but when they experience outgroup bias, they might believe more in its reasonability.

Our results are in line with observations in the real world that, when information is imperfect, people will make more use of the information they believe to be contained in a category a person belongs to under strong(er) competition - no matter how relevant the categories really are for an estimation of productivity. If categories contain real productivityrelated information, the result will be statistical discrimination against individuals. If categories do not contain such information, the result will be group as well as individual discrimination - the weak form of statistical discrimination.

The experiments also showed that outgroup bias is possible, especially when competition is strong and the ingroup is perceived as performing badly. This is rarely discussed in the psychological literature (but, see, e.g., Spears et al.). However, preconditions for this to happen in the real world are probably (i) that decision makers assume that their own group performs badly in the task at hand and (ii) that general identification with the ingroup is not very high. In the real world, identification with one's own category is stronger than in the laboratory with artificial categories, and this might be even more so when 
competition is strong. Precondition (i) also often does not hold with respect to real categories, as it is not very probable that e.g. men really start to think that men in general perform worse than women in a certain (male-dominated) task. Stressing positive aspects of the outgroup or of diversity might help reducing discriminatory tendencies against outgroups when competition is strong at the same time. It could, however, also be threatening for the ingroup. Such a threat could then lead to stronger identification, or to focusing on other qualities of the own group. In the end, stressing positive aspects of the outgroup might, by these psychological effects, even lead to stronger discrimination.

For future research it would be important to do similar studies with real categories (to allow for prejudice to influence behavior), and to construct experimental designs where subjects have the possibility to search for individual information in addition to the category information, to see in how far they still rely on category-based information.

To conclude, the experiments showed that it is very difficult to test for discriminatory behavior in the labor market in experimental settings in the laboratory. They however also showed that it is possible to do so, and that interesting results can be achieved both with respect to theory testing and with respect to a better understanding of the processes underlying discriminatory behavior. Therefore, we hope that in the future more experimental research is done in this area, to complement theoretical and empirical studies analyzing discrimination on the labor market both in economics and in social psychology.

\section{Appendix Relation between experimental $\widetilde{D} / p$ and theoretical $D / p$}

The relation between the experimental 'real' discrimination coefficient $\widetilde{D} / p$ and the theoretical $D / p$ can be derived as follows. Assume that the subjects choose $\widetilde{D} / p$ approximately in such a way that it maximizes the expected profit gain of their team from getting a preferred new member or not, $E[\Delta R-\widetilde{D}]=E \Delta R-\widetilde{D} \cdot{ }^{12}$ Here $\Delta R$ is the expected

\footnotetext{
${ }^{12}$ Strictly speaking, subjects should maximize $E[(1 / 5) \Delta R-(1 / 4) \widetilde{D}]$ since revenues are shared among the five members of the extended team including the new member, whereas the payment $\widetilde{D}$ is shared among the four
} 
additional revenue from getting a preferred new member or not over the three rounds that are played with the new member, i.e. $\Delta R=3 p \Delta \hat{q}=3 p S \Delta \bar{q}^{S}$ when a team member from the preferred category is assigned to the team, and $\Delta R=0$ when a team member from the other category is assigned. Thus, $\Delta R$ is stochastic. The probability $\rho$ of getting a new member from the preferred category depends on $\widetilde{D} / p$ as

$$
\begin{array}{ll}
\rho=0.5+\beta \widetilde{D} / p & \text { for } \widetilde{D} / p \leq \widetilde{D}_{\text {max }} / p=1 /(2 \beta), \\
\rho=1 & \text { for } \widetilde{D} / p \geq \widetilde{D}_{\text {max }} / p=1 /(2 \beta),
\end{array}
$$

where $\beta$ is a positive parameter. Hence,

$$
\begin{aligned}
E \Delta R-\widetilde{D} & =\rho 3 p S \Delta \bar{q}^{S}+(1-\rho) 0-\widetilde{D}=3(0.5+\beta \widetilde{D} / p) p S \Delta \bar{q}^{S}-\widetilde{D}= \\
& =\left(3 \beta S \Delta \bar{q}^{S}-1\right) \widetilde{D}+1.5 p S \Delta \bar{q}^{S}
\end{aligned}
$$

for $\widetilde{D} / p \leq 1 /(2 \beta)$, and $E \Delta R-\widetilde{D}=3 p S \Delta \bar{q}^{S}-\widetilde{D}$ for $\widetilde{D} / p \geq 1 /(2 \beta)$. The latter function is decreasing in $\widetilde{D}$, while function (A.2) is linearly increasing or decreasing in $\widetilde{D}$, dependent on the sign of the expression in front of $\widetilde{D}$. Thus, we have three cases:

(i) $3 \beta S \Delta \bar{q}^{S}<1$ or $S \Delta \bar{q}^{S}<1 /(3 \beta)$

(ii) $3 \beta S \Delta \bar{q}^{S}=1$ or $S \Delta \bar{q}^{S}=1 /(3 \beta)$

(iii) $3 \beta S \Delta \bar{q}^{S}>1$ or $S \Delta \bar{q}^{S}>1 /(3 \beta)$

In case (i) function (A.2) is linearly decreasing in $\widetilde{D}$, implying that $E \Delta R-\widetilde{D}$ is maximal for $\widetilde{D} / p=0$, so perception $\Delta \hat{q}=S \Delta \bar{q}^{S}$ is not large enough to make it advantageous to pay an amount of money to raise the chance of getting a new team member from the preferred category. In case (iii) function (A.2) is linearly increasing in $\widetilde{D}$, implying that $E \Delta R-\widetilde{D}$ is maximal for $\widetilde{D} / p=\widetilde{D}_{\max } / p=1 /(2 \beta)$, so perception $\Delta \hat{q}=S \Delta \bar{q}^{S}$ is large enough to make it advantageous to pay the minimal amount of money that raises the chance of getting a new team member from the preferred category to one. In the intermediate case (ii) function (A.2) is constant with respect to $\widetilde{D}$, implying that $E \Delta R-\widetilde{D}$ is maximal for all values of $\widetilde{D} / p$

old members. However, we assume that subjects do not take this minor complication into account in their choice of $\widetilde{D}$. 
between 0 and $1 /(2 \beta)$. Plotting the optimal $\widetilde{D} / p$ as a function of $S \Delta \bar{q}^{S}=D / p$ we then get the stepwise graph in Fig. 1.

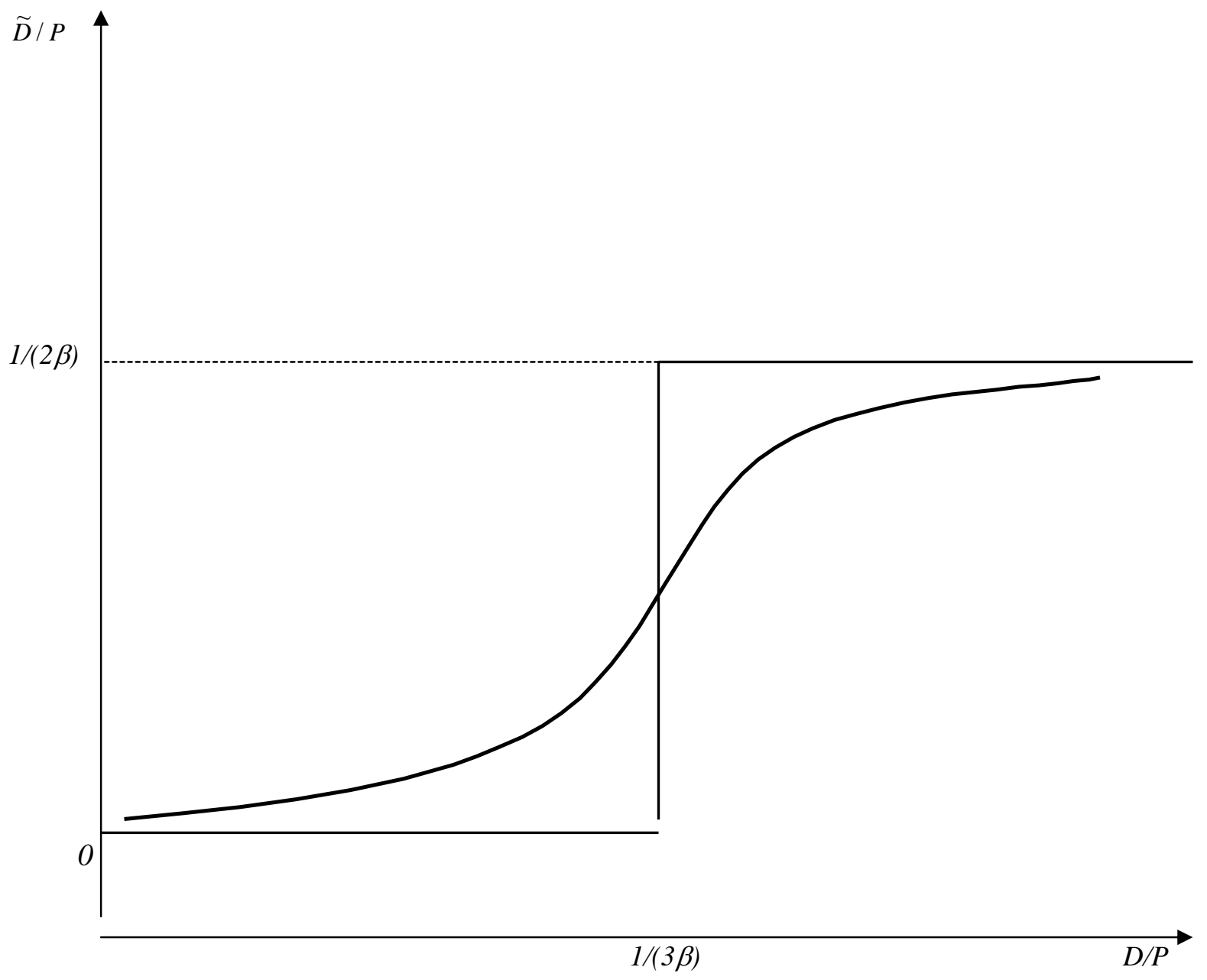

Figure 1: The optimal $\widetilde{D} / P$ as a function of $S * \Delta M P=D / P$

However, we can safely presume that the subjects in the experiment chose their $\widetilde{D} / p$ not on the basis of such a precise calculation, but in a much more intuitive way. On the other hand, we may assume that their intuition led to choices of $\widetilde{D} / p$ which form a smooth approximation of the stepwise graph in Fig. 1. Such an approximation is indicated by the bold smooth sigmoid curve in Fig. 1. A curve of this shape implies that the experimental $\widetilde{D} / p$ is a 
monotonously increasing function of the theoretical $D / p$ for not too low and not too high values of $D / p$. Another implication of the sigmoid shape of the curve in Fig. 1 is that the variation in $\widetilde{D} / p$ as a function of $D / p$ is the strongest for values of $D / p$ around $1 /(3 \beta)$. Therefore, in order to make the probability of significant differences in $\widetilde{D} / p$, and hence in $D / p$, under different strengths of competition as high a possible, we chose the value of $\beta$ in such a way that $1 /(3 \beta)$ is roughly equal to an a priori guess of the order of magnitude of the average value of $D / p=S \Delta \bar{q}^{S}$ under the different strengths of competition. In the context of the experiments our guess of this order of magnitude was 0.5 (point), implying a value of $\beta$ of $1 / 1.5=2 / 3$. The maximal value $\widetilde{D}_{\max } / p=1 /(2 \beta)$ in Fig. 1 , for which $\rho=1$ (see eq. (A.1)), is then equal to $1 /(4 / 3)=0.75$. Thus, by paying $15 \%$ of the output price $(\widetilde{D} / p=0.15$ in eq. (A.1) the probability $\rho$ of getting a new team member from the preferred category was raised by $(2 / 3) \cdot 15=10 \%$.

\section{References}

Arrow, Kenneth J., 1973. The Theory of Discrimination, In: O. Ashenfelter and A. Rees (Eds.), Discrimination in Labor Markets. Princeton University Press, Princeton, pp. 3-33.

Becker, Gary, 1957. The Economics of Discrimination. The University of Chicago Press, Chicago.

Bell, S., Eckel, C., Grossman, P. J., Zame, W., 2001. Status in Markets. The Quarterly Journal of Economics 116, $161-188$.

Comanor, W. S., 1973. Racial Discrimination in American Industry. Economica, 40, 363 378.

Eagly, A. H. and Chaiken, S., 1998. Attitude Structure and Function, In: S. T. Fiske, D. T. Gilbert, G. Lindsay (Eds.), The Handbook of Social Psycchology, Vol. 1. McGraw Hill, New York, pp. 269-322.

Fershtman, C., and Gneezy, U., 2001. Discrimination in a segmented society: An experimental approach. The Quarterly Journal of Economics 166, 351 - 377. 
Fiedler, Klaus, 2000. Beware of Samples! A Cognitive-Ecological Sampling Approach to Judgment Biases. Psychological Review 107, 659 - 676.

Fiedler, K., Walther, E., Nickel, S., 1999. The Auto-Verification of Social Hypotheses: Stereotyping and the Power of Sample Size. Journal of Personality and Social Psychology $77,5-18$.

Fischbacher, Urs, 1999. z-Tree: Toolbox for Readymade Economic Experiments. IEW Working Paper 21, University of Zurich.

Greenwald, A. G., and Banaji, M. R., 1995. Implicit social cognition: Attitudes, self-esteem, and stereotypes. Psychological Review 102, 4-27.

Haslam, S. A., Oakes, P., Turner, J. C., 1996. Social Identity, Self-Categorization, and the Perceived Homogeneity of Ingroups and Outgroups: The interaction Between Social Motivation and Cognition, In: R. M. Sorrentino and E. T. Higgins (Eds.), Handbook of Motivation and Cognition, Vol. 3: The Interpersonal Context, Guildford, New York, pp. $182-222$

Hertwig, R. and Ortmann, A., 2001. Experimental practices in economics: A methodological challenge for psychologists? Behavior and Brain Sciences 24, 383-451.

Mullin, B. A., and Hogg, M. A., 1998. Dimensions of subjective uncertainty in social identification and minimal intergroup discrimination. British Journal of Social Psychology 37, 345-365.

Phelps, Edmund S., 1972. The Statistical Theory of Racism and Sexism. American Economic Review 62, 659-661.

Vendrik, M. and Schwieren, C., 2004. Identification, screening and stereotyping in labor market discrimination. Working paper, Department of Economics, Maastricht University.

Spears, R., Jetten, J., Doosje, B., 2001. The (il)legitimacy of ingroup bias: From social reality to social resistance, In: B. Major and J. Jost (Eds.), The Psychology of Legitimacy: Emerging Perspectives on Ideology, Justice, and Intergroup Relations. New York: Cambridge University Press, New York, pp. $332-363$.

Tajfel, H., Billig, M. G., Bundy, R. P., Flament, C., 1971. Social categorization and intergroup behavior. European Journal of Social Psychology 1, 149-178. 
Turner, J. C. and Oakes, P. J., 1986. The Significance of the Social Identity Concept for Social Psychology with Reference to Individualism, Interactionism and Social Influence. British Journal of Social Psychology 25, 237-252. 